\title{
Topical Treatment of Infantile Haemangiomas: A Comparative Study on the Selection of a Semi-Solid Vehicle
}

\author{
Antonella Casiraghi ${ }^{a}$ b Umberto M. Musazzi ${ }^{a}$ Paolo Rocco ${ }^{a}$ Silvia Franzèa \\ Paola Minghetti ${ }^{a, b}$ \\ ${ }^{a}$ Department of Pharmaceutical Sciences, and ${ }^{b}$ School of Specialisation in Hospital Pharmacy, Università degli Studi \\ di Milano, Milan, Italy
}

\section{Key Words}

Haemangiomas · Propranolol · Topical delivery · Semi-solid preparations · Skin permeation · Vehicle selection

\begin{abstract}
Background/Aim: Topical $\beta$-blockers have recently been proposed as a valid alternative to oral drugs for treating cutaneous infantile haemangiomas, but clinical results in the literature are inconsistent due to the empirical choice of topical preparations. The current investigation aimed to rationalize the selection of a semi-solid vehicle for a locally applied drug product containing $1 \% \mathrm{w} / \mathrm{w}$ propranolol hydrochloride (PR-Cl). Methods: A hydrophobic ointment of PR-Cl, two lipophilic creams, and a hydrophilic cream were prepared. In vitro release and skin permeation studies through human epidermis and full-thickness skin were performed by Franz diffusion cells. Results: The overall results highlighted that PR-CI was able to permeate the human epidermis, and its penetration pattern was strongly influenced by the composition of the semi-solid vehicle. PR-Cl release and permeation from lipophilic vehicles were extremely limited and influenced by their composition. Best results were obtained by using the hydrophilic cream. Furthermore, the retention study evidenced that epidermis acted as a reservoir, releasing the PR-
\end{abstract}

$\mathrm{Cl}$ accumulated after preparation removal. Conclusion: The $1 \% \mathrm{w} / \mathrm{w}$ PR-Cl cream resulted the most suitable formulation for improving drug permeation through the human epidermis. On the contrary, the negligible permeation profile through full-thickness skin pointed out that PR-Cl cannot diffuse significantly to reach the deeper layers of human skin.

(c) 2016 S. Karger AG, Basel

\section{Introduction}

Propranolol (PR) is widely accepted by the paediatrician community as first-line therapy for the management of infantile haemangiomas (IH) $[1,2]$, which are the most common benign tumours of infancy and affect $2 \%$ of infants and around $12 \%$ of children under 12 years of age. IH are characterized by a rapid and intermittent growth of the tumour mass followed by a spontaneous regression in most cases. Although IH spontaneously evolve in $90 \%$ of cases, pharmacological treatments or surgery are frequently required to prevent disfigurement and functional impairment (e.g., obstruction of airways and vision, cardiac insufficiency, and hypothyroidism) [2] .

PR effectiveness was firstly documented in 2008, when Léauté-Labrèze et al. [3] observed a rapid regression of IH

\section{KARGER}

E-Mail karger@karger.com

www.karger.com/spp
(C) 2016 S. Karger AG, Basel

$1660-5527 / 16 / 0294-0210 \$ 39.50 / 0$
Antonella Casiraghi

Department of Pharmaceutical Sciences, Università degli Studi di Milano Via G. Colombo 71

IT-20133 Milan (Italy)

E-Mail antonella.casiraghi@unimi.it 
Table 1. Clinical studies evaluating topical PR in treating cutaneous IH

\begin{tabular}{|c|c|c|c|c|c|c|}
\hline Authors [ref.], year & Study design & $\begin{array}{l}\text { Patients, } \\
\mathrm{n}\end{array}$ & Topical preparation & $\begin{array}{l}\mathrm{PR}-\mathrm{Cl} \text { con- } \\
\text { centration, } \\
\%\end{array}$ & Daily dose & $\begin{array}{l}\text { Response } \\
\text { rate, } \\
\%\end{array}$ \\
\hline Wang et al. [11], 2012 & Prospective cohort & 51 & Chitosan gel & 3 & Thrice & 92 \\
\hline Xu et al. [10], 2012 & Retrospective cohort & 25 & Solid dispersion & 1 & Thrice & 90 \\
\hline Kunzi-Rapp [9], 2012 & Prospective cohort & 45 & Hydrophilic ointment & 1 & Twice & 64 \\
\hline Bonifazi et al. [7], 2008 & Prospective cohort & 6 & Oil-based cream & 1 & Twice & 67 \\
\hline
\end{tabular}

in a patient who received the $\beta$-blocker for the treatment of pre-existent cardiovascular disease. In the last decade, other clinical trials have supported the replacement of oral corticosteroids with oral PR as first-line treatment due to its higher effectiveness and lower risk of side effects [4-6]. Meanwhile, topical preparations containing PR hydrochloride (PR-Cl) and timolol have been proposed as an alternative treatment for superficial $\mathrm{IH}$, especially for treating newborn infants (table 1) [1,7-11]. Although the published data seem to demonstrate the clinical efficacy of topical PR, therapeutic protocols and guidelines have not yet been established. Indeed, the results of clinical studies published in the literature are ambiguous due to the empirical choice of semi-solid bases other than the differences in clinical protocols (e.g., study design, selection of patients, and end points) [12].

To be efficacious, the semi-solid drug product has to release enough PR-Cl to guarantee a sufficient drug concentration at the interface with the human epidermis to sustain its permeation through the stratum corneum and, consequently, to reach therapeutic concentrations at the target site. In general, drug permeation through the human epidermis is a passive diffusion process that depends on both the physicochemical properties of the drug (e.g., molecular weight, $\log \mathrm{P}$ ) and vehicle. In the case of PR, several studies have demonstrated a good permeation profile through human skin, but this process is strongly related to its ionization rate and the type of counter ions [13, 14]. On the other hand, the composition of the semi-solid vehicle is also critical because it strongly influences the drug physicochemical stability and its release and permeation profiles [15-17]. Moreover, the introduction of other excipients, such as preservative, to the composition of the semisolid product should also be carefully considered since they can alter the inner environment of the semi-solid matrix, modifying its effectiveness in drug delivery. Therefore, the selection of an appropriate vehicle and the ratio- nalization of its composition should be carefully studied as these might influence the clinical efficacy of the drug product by the modification of the drug permeation profile; the previously reported case of $\mathrm{PR}-\mathrm{Cl}$ is an example.

This study focused on investigating in vitro how the permeation profile of $\mathrm{PR}-\mathrm{Cl}$ could be influenced by the choice of the semi-solid vehicle. In particular, four vehicles were chosen among well-known semi-solid bases that were widely used by compounding pharmacists and were similar to preparations already tested in vivo in the existing literature $[1,9,10]$. The formulations were compared in terms of drug release and permeation through the human epidermis and full-thickness skin. These model membranes were selected to sustain in vitro the clinical evidence of topical PR in treating IH with superficial and deep elements. Furthermore, the addition of the preservative methylparaben and its influence on the permeation pattern were also investigated.

The outcomes of the study may be of particular interest to compounding pharmacists in preparing extemporaneous preparations in hospital and community pharmacies, especially when, as in the case of the use of PR-Cl for treating $\mathrm{IH}$, no industrial medicinal products are available on the market.

\section{Materials and Methods}

\section{Materials}

$\mathrm{PR}-\mathrm{Cl}$ and sodium methylparaben were purchased from Farmalabor Srl. (Italy). White petrolatum, lanolin, and lanolin alcohols were purchased form A.C.E.F. Spa. (Italy). Mineral oil, cetostearyl alcohol, and cetomacrogol 1000 were purchased from Carlo Erba Reagents Srl. (Italy). Cuprophan ${ }^{\circledR}$ membranes were purchased from Akzo Nobel Faser (Germany). High-performance liquid chromatography (HPLC)-grade acetonitrile was purchased from VWR International PBI Srl. (Italy). All other reagents and solvents were purchased from Sigma-Aldrich Srl. (Italy) and used without further purification. 
Table 2. Solubility parameters $(\delta)$ of $\mathrm{PR}-\mathrm{Cl}$ and lipophilic ingredients; composition of semi-solid preparations $\left(\mathrm{F}_{0}-\mathrm{F}_{4}\right)$ and water solutions $\left(\mathrm{S}_{1}-\mathrm{S}_{6}\right)$ containing $1 \% \mathrm{w} / \mathrm{w} \mathrm{PR}-\mathrm{Cl}$

\begin{tabular}{|c|c|c|c|c|c|c|c|c|c|c|c|c|}
\hline Ingredients & $\delta, \mathrm{cal} / \mathrm{cm}^{3}$ & \multicolumn{11}{|c|}{ Formulation composition, $\% \mathrm{w} / \mathrm{w}$} \\
\hline White petrolatum & $7.33^{\mathrm{b}}$ & 99.00 & 79.30 & 41.40 & 15.00 & 15.00 & - & - & - & - & - & - \\
\hline Lanolin alcohol & $9.55^{\mathrm{c}}$ & - & 5.10 & - & - & - & - & - & - & - & - & - \\
\hline Cetostearyl alcohol & $9.49^{\mathrm{b}}$ & - & 0.40 & - & 7.25 & 7.25 & - & - & - & - & - & - \\
\hline Cetomacrogol 1000 & $9.40^{\mathrm{b}}$ & - & - & - & 1.80 & 1.80 & - & - & - & - & - & - \\
\hline Sodium methylparaben & - & - & 0.05 & 0.05 & 0.05 & - & 0.05 & - & 0.05 & - & 0.05 & - \\
\hline PBS at $\mathrm{pH} 9.0$ & - & - & - & - & - & - & - & - & 98.95 & 99.00 & - & - \\
\hline PBS at pH 5.8 & - & - & - & - & - & - & - & - & - & - & 98.95 & 99.00 \\
\hline Purified water & - & - & 14.15 & 16.15 & 68.90 & 68.95 & 98.95 & 99.00 & - & - & - & - \\
\hline
\end{tabular}

${ }^{\mathrm{a}}$ Maitani et al. [21]. ${ }^{\mathrm{b}}$ Minghetti et al. [16]. ${ }^{\mathrm{c}}$ Vaughan [20].

Preparation of Aqueous Solutions Containing PR-Cl

PR-Cl solutions $(1 \% \mathrm{w} / \mathrm{w})$ were prepared in different solvents: HPLC-grade water, phosphate buffer solution (PBS) at $\mathrm{pH} 9.0$ (4008300, Eur. Ph. 8.8), and PBS at pH 5.8 (4002100, Eur. Ph. 8.8). The solutions were obtained dissolving a weighted drug amount in the three solvent media with $\left(\mathrm{S}_{1}, \mathrm{~S}_{3}, \mathrm{~S}_{5}\right)$ or without the addition of methylparaben $\left(\mathrm{S}_{2}, \mathrm{~S}_{4}, \mathrm{~S}_{6}\right.$; table 2$)$.

\section{Preparation of Semi-Solid Formulations Containing PR-Cl}

The PR-Cl was incorporated at the concentration of $1 \% \mathrm{w} / \mathrm{w}$ into a hydrophobic ointment, two lipophilic creams, and a hydrophilic cream (table 2). The hydrophobic ointment $\left(\mathrm{F}_{0}\right)$ was made by adding the $\mathrm{PR}-\mathrm{Cl}$ to white petrolatum by geometric trituration. The lipophilic $\left(\mathrm{F}_{1}, \mathrm{~F}_{2}\right)$ and hydrophilic creams $\left(\mathrm{F}_{3}\right)$ were made by a melt emulsification process. Briefly, the lipophilic components were melted at $45-50^{\circ} \mathrm{C}$ under constant magnetic stirring. At the same time, the $\mathrm{PR}-\mathrm{Cl}$ and sodium methylparaben were dissolved in purified water for dispersing the drug homogeneously in the semi-solid matrix, warmed up to $40^{\circ} \mathrm{C}$, and then mixed into the melt lipophilic phase. The magnetic stirring was kept constant during the entire preparation process. At the end, the system was cooled to room temperature and the final preparation was stored at $25^{\circ} \mathrm{C}$ until use. In order to evaluate the effect of the preservative on in vitro skin permeation profiles, a batch of hydrophilic cream without sodium methylparaben was also prepared $\left(\mathrm{F}_{4}\right)$.

\section{In vitro Release Study}

The in vitro release studies were performed using Franz diffusion cells (permeation area: $0.636 \mathrm{~cm}^{2}$; volume of receptor chamber about $3 \mathrm{ml}$ ) and Cuprophan ${ }^{\circledR}$ as the synthetic release membrane. Prior to the experiments, the Cuprophan ${ }^{\circledR}$ membrane was hydrated in $0.9 \% \mathrm{w} / \mathrm{v} \mathrm{NaCl}$ solution for $1 \mathrm{~h}$. At the beginning of the experiment, the PR-Cl-loaded semi-solid formulations (120 $\mathrm{mg}$ ) were applied to the surface of the Cuprophan ${ }^{\circledR}$ membrane in a 1-mm-thick layer by means of an excavated polyethylene disk. Then, the sample was mounted on the Franz diffusion cells, whose receptor compartments were filled with degassed $0.9 \% \mathrm{w} / \mathrm{v} \mathrm{NaCl}$ solution containing $100 \mu \mathrm{g} / \mathrm{ml} \mathrm{NaN}$ as preservative. Special care was given to avoid air bubbles between the membrane and the solution in the receptor compartment. The upper and lower parts of the Franz cells were sealed with Parafilm ${ }^{\circledR}$ and fastened together by means of a clamp. The system was kept at $37^{\circ} \mathrm{C}$ with a circulating water bath, so that the membrane surface temperature was at $32 \pm 1{ }^{\circ} \mathrm{C}$ throughout the experiment. At predetermined times $(1,3,5,7$, and $24 \mathrm{~h}), 200-\mu \mathrm{l}$ samples were withdrawn from the receiver compartment and analysed by HPLC. The withdrawn aliquot was replaced with the same volume of fresh receiver medium. Sink conditions were maintained throughout the experiments. The results were expressed as the average of parallel experiments performed in triplicate. The cumulative amount released $\left(\mathrm{Q}_{\mathrm{R}, \mathrm{t}}\right)$ from the semi-solid formulation per unit area was calculated from the drug concentration in the receiving medium and plotted as a function of time. In agreement with the Higuchi equation [18], the rate of drug release is calculated as the slope of the cumulative released amount plotted versus the square root of time between 1 and $7 \mathrm{~h}$.

\section{In vitro Skin Permeation Study}

The in vitro permeation and retention studies were performed using human epidermis as membrane. The human epidermis originated from the abdominal skin of a donor who underwent cosmetic surgery. The full-thickness skin was sealed in evacuated plastic bags and stored within $6 \mathrm{~h}$ after removal. Epidermis samples were prepared following an internal standard procedure [19]. Briefly, prior to the experiments, the skin was thawed at room temperature, and excess fat was carefully removed. The skin sections were cut into squares of about $4.0 \mathrm{~cm}^{2}$ and, after immersion in water at $60^{\circ} \mathrm{C}$ for $1 \mathrm{~min}$, the epidermis was gently separated from the remaining tissue with a forceps.

At the beginning of the permeation experiment, the tested formulations were applied on the stratum corneum of each epidermis sample. In particular, $0.5 \mathrm{ml}$ of $\mathrm{PR}-\mathrm{Cl}$ solution was loaded directly in the donor compartment of each cell, whereas about $120 \mathrm{mg}$ of semi-solid formulation containing $\mathrm{PR}-\mathrm{Cl}$ were applied using the 
Table 3. In vitro release $\left(Q_{R, 24}\right.$ and release rates) and skin permeability $\left(\mathrm{Q}_{\mathrm{P}, 2}\right.$ and $\left.\mathrm{Q}_{\mathrm{ret}}\right)$ parameters of the tested semi-solid formulations $\left(\mathrm{F}_{0}-\mathrm{F}_{3}\right)$

\begin{tabular}{lcrll}
\hline & $\begin{array}{l}\mathrm{Q}_{\mathrm{R}, 24}, \\
\mu \mathrm{g} / \mathrm{cm}^{2}\end{array}$ & $\begin{array}{l}\text { Release rate } \\
\mu \mathrm{g} / \mathrm{cm}^{2} / \mathrm{h}^{1 / 2}\end{array}$ & $\begin{array}{l}\mathrm{Q}_{\mathrm{P}, 24,}, \\
\mu \mathrm{g} / \mathrm{cm}^{2}\end{array}$ & $\begin{array}{l}\mathrm{Q}_{\text {ret,24, }} \\
\mu \mathrm{g} / \mathrm{cm}^{2}\end{array}$ \\
\hline $\mathrm{F}_{0}$ & $6.11 \pm 2.73$ & $0.57 \pm 0.59$ & - & $13.19 \pm 6.61$ \\
$\mathrm{~F}_{1}$ & $31.11 \pm 5.60$ & $4.16 \pm 1.88$ & $0.50 \pm 0.27$ & $34.27 \pm 4.27$ \\
$\mathrm{~F}_{2}$ & $69.42 \pm 9.81$ & $12.71 \pm 3.35$ & $14.99 \pm 8.52$ & $54.57 \pm 19.72$ \\
$\mathrm{~F}_{3}$ & $1,306.66 \pm 211.32$ & $307.55 \pm 84.86$ & $52.22 \pm 7.34$ & $94.96 \pm 4.11$ \\
\hline
\end{tabular}

Values are means \pm SD $(n=3)$.

a 1724 - Semisolid drug products, performance tests. USP 38.

same polyethylene disk as for the release study. Then, the in vitro permeation study was carried out following the same experimental protocol as described above. The receptor phase samples collected during the experiment were analysed by HPLC. The results obtained were expressed as the average of parallel experiments performed in triplicate. Furthermore, the best formulations in terms of release and permeation profiles were re-tested using full-thickness skin as membrane.

The cumulative amount permeated through the skin per unit area $\left(Q_{P}\right)$ was calculated from the drug concentration in the receiving medium and plotted as a function of time. The steady-state flux (J) was determined as the slope of the linear portion of the plot.

\section{In vitro Retention Studies}

At the end of the permeation experiments, the epidermis sheet was removed from the Franz diffusion cell, and each side was gently treated with $5 \mathrm{ml}$ of methanol to wash out the unabsorbed drug. Subsequently, the sample was dried, thinly sliced, and placed in $5 \mathrm{ml}$ of fresh methanol. The suspension was soaked in a sonicator for $30 \mathrm{~min}$ and then maintained for $24 \mathrm{~h}$ at $2-8^{\circ} \mathrm{C}$. Finally, the supernatant was filtered at $0.22 \mu \mathrm{m}$ and analysed by HPLC. The results were expressed as the average of parallel experiments performed in triplicate. The retained drug amount $\left(\mathrm{Q}_{\mathrm{ret}}\right)$ was expressed as micrograms of $\mathrm{PR}-\mathrm{Cl}$ per unit area of epidermis.

In order to evaluate the ability of the epidermis to act as a reservoir compartment during the drug biodistribution, the $\mathrm{PR}-\mathrm{Cl}$ amount released from the epidermis after the removal of the formulation used in the permeation experiments was further investigated. At the end of the permeation experiments, the epidermis was removed from the Franz diffusion cell and the semi-solid formulation was accurately discarded from the upper side. To wash out the unpenetrated drug, the epidermis was gently treated with $10 \mathrm{ml}$ of $0.9 \% \mathrm{w} / \mathrm{v} \mathrm{NaCl}$ solution to avoid any possible damage to the epidermis structure. Then, the epidermis sheets were remounted on the Franz diffusion cells filled with fresh receptor phases following the same procedures as the in vitro permeation study. At predetermined times (1, 3, 5, 7, and $24 \mathrm{~h}$ ), 200- $\mu \mathrm{l}$ samples were withdrawn and analysed by HPLC according to the method described above. The results were expressed as the average of parallel experiments performed in triplicate. The cumulative amount released from the epidermis per unit area was calculated from the drug concentration in the receiving medium and plotted as a function of time.

Propranolol-Loaded Semi-Solid

Preparations for Treating Haemangiomas

\section{HPLC Analyses}

The amount of PR-Cl was determined by HPLC (HP 1100 ChemStations; Agilent Technologies, USA) equipped with an ultraviolet detector at $230 \mathrm{~nm}$. Phosphate buffer $\mathrm{pH}$ 2.5/acetonitrile $(70 / 30 \%, \mathrm{v} / \mathrm{v})$ was used as mobile phase at a flow rate of $1.5 \mathrm{ml} / \mathrm{min}$, and the analysis temperature was fixed at $25^{\circ} \mathrm{C}$. The compound separation was carried out using a reverse-phase column (Hypersil Gold, $5 \mu \mathrm{m}, 150 \times 4.6 \mathrm{~mm}$; Thermo Fisher Scientific Inc., USA), and the injection volume was set at $20 \mu$ l. The retention time of $\mathrm{PR}-\mathrm{Cl}$ was $3.0 \mathrm{~min}$ and three calibration curves were made in the overall range of $0.02-160 \mu \mathrm{g} / \mathrm{ml}$.

\section{Solubility Parameter}

The solubility parameter $(\delta)$ of a material was defined as the square root of the cohesive energy density as described by equation (Eq.) 1:

$$
\delta=\sqrt{\frac{\Delta E V}{V_{m}}},
$$

where $\Delta \mathrm{EV}$ represents the energy of vaporization and $\mathrm{V}_{\mathrm{m}}$ is the molar volume of the material. As reported in table 2 , the $\delta$ values of each of the lipophilic ingredients of the semi-solid formulation were derived from the literature $[16,20,21]$. Since no $\delta$ values for lanolin and its alcohols were reported in literature, their solubility parameters were estimated to be equal to the $\delta$ value of the cholesterol, which was the most abundant component in the lanolin compositions. As the solubility parameter was an additive property, the $\delta$ values for tested formulations (table 2) were derived according to the following Eq. 2:

$$
\delta=\sum \delta_{i} \varphi_{i}
$$

where $\delta_{\mathrm{i}}$ is the solubility parameter of the excipient and $\varphi_{\mathrm{i}}$ is its volume fraction [22].

\section{Data Analysis}

The performance of the samples and the correlation between the release data and the permeation/retention ones were compared by the Student $t$ test (Excel $2013{ }^{\circledR}$; Microsoft, USA). The level of significance was taken as $\mathrm{p}<0.05$.

\section{Results}

\section{In vitro Release Study}

As shown in table 3, the hydrophilic cream $\left(\mathrm{F}_{3}\right)$ was the best formulation in terms of $\mathrm{Q}_{\mathrm{R}, 24}$ and release rate. Indeed, the formulation $\mathrm{F}_{3}$ released around $20 \% \mathrm{w} / \mathrm{w}$ of loaded drug within $1 \mathrm{~h}$ and $74.70 \pm 14.90 \%$ at $24 \mathrm{~h}$. On the other hand, the hydrophobic ointment $\left(\mathrm{F}_{0}\right)$ showed a negligible release rate, and less than $1 \%$ of loaded drug was released during the entire experiment. The release performances of the two lipophilic creams could be considered to be between these two extremes. In particular, the release rate of both $F_{1}$ and $F_{2}$ creams was significantly higher in comparison to $\mathrm{F}_{0}(\mathrm{p}<0.03)$ and more than 20 times lower than the $\mathrm{F}_{3}$ cream $(\mathrm{p}<0.01$; table 3$)$. How- 


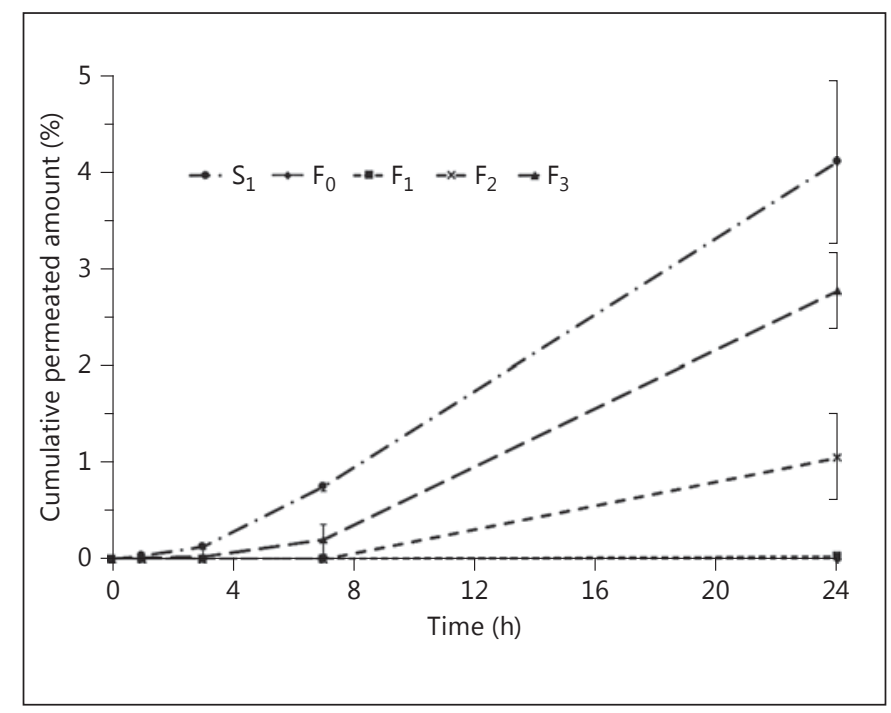

Fig. 1. In vitro permeation profiles through the human epidermis of the reference solution $\left(\mathrm{S}_{1}\right)$ and the semi-solid preparations $\left(\mathrm{F}_{0}-\right.$ $\left.\mathrm{F}_{3}\right)$ containing $1 \% \mathrm{w} / \mathrm{w}$ of $\mathrm{PR}-\mathrm{Cl}(\mathrm{n}=3$, mean $\pm \mathrm{SD})$.

ever, the release rate of the $\mathrm{F}_{2}$ formulation was 3 times higher than $F_{1}$ within $7 \mathrm{~h}(\mathrm{p}<0.05)$, whereas the $\mathrm{Q}_{\mathrm{R}, 24}$ result was twice as high $(\mathrm{p}<0.01)$.

\section{In vitro Skin Permeability Study}

The amounts permeated by $\mathrm{PR}-\mathrm{Cl}$ measured by using the semi-solid preparations were lower in comparison to those of the $S_{1}$ reference solution (fig. 1). After a time lag of about $2 \mathrm{~h}$, the permeation of the $\mathrm{S}_{1}$ solution resulted in a linear profile $\left(\mathrm{R}^{2}=0.992\right)$ with a steady-state flux of $15.40 \pm 3.17 \mu \mathrm{g} / \mathrm{cm}^{2} / \mathrm{h}$. A similar trend was also observed for the hydrophilic cream $\left(\mathrm{F}_{3}\right)$, although the permeation flux was lower (J: $2.70 \pm 0.33 \mu \mathrm{g} / \mathrm{cm}^{2} / \mathrm{h}$ ) and lag time slightly higher $(164 \mathrm{~min})$ than those of $S_{1}$. On the other hand, the steady-state fluxes of creams $F_{1}$ and $F_{2}$ cannot be calculated within $24 \mathrm{~h}$ since the lag time was greater than $8 \mathrm{~h}$. The formulation $\mathrm{F}_{2}$ resulted in a higher $\mathrm{Q}_{\mathrm{P}, 24}$ in comparison to formulation $\mathrm{F}_{1}$ (table 3). The $\mathrm{Q}_{\mathrm{P}, 24}$ was always below the limits of quantification of the analytical method in the case of hydrophobic ointment. In any case, the cumulative permeated amounts at the end of the experiments did not exceed the $5 \% \mathrm{w} / \mathrm{w}$ of the initial drug loading both for the solutions and for all the semi-solid formulations.

The results of the retention study confirmed the permeability trend, and they highlighted a linear correlation between $\mathrm{Q}_{\mathrm{P}, 24}$ and $\mathrm{Q}_{\text {ret }}\left(\mathrm{R}^{2}=0.92\right)$. When $\mathrm{PR}-\mathrm{Cl}$ was test-

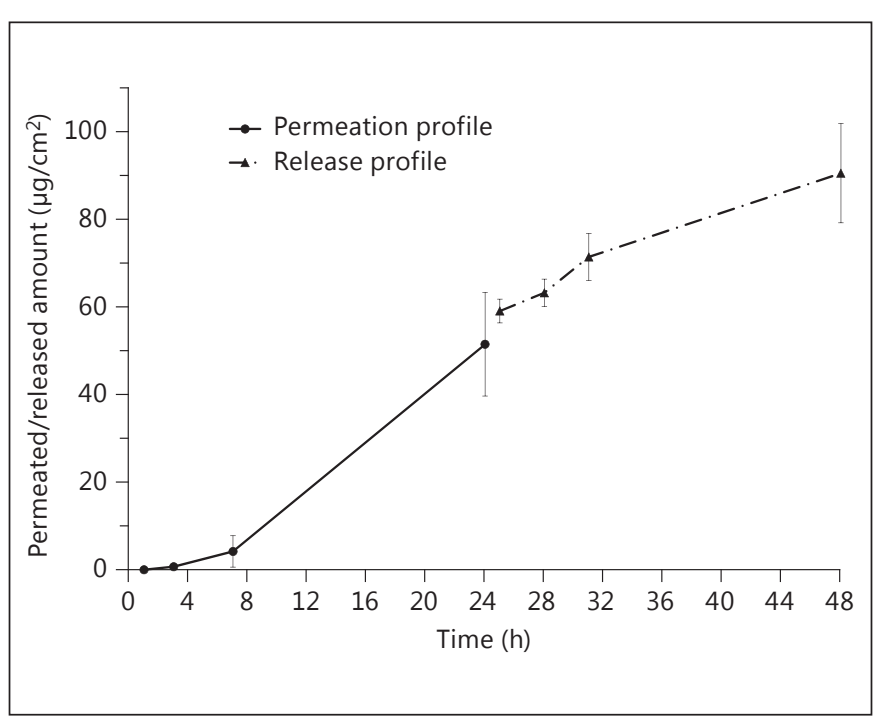

Fig. 2. PR-Cl-permeated amounts through the human epidermis during a 24-hour permeation study delivered by $1 \%$ PR-Cl hydrophilic cream and those released from the same membrane after the preparation removal $(n=3$, mean $\pm S D)$.

ed as water solution $\left(\mathrm{S}_{1}\right)$, the $\mathrm{Q}_{\text {ret }}$ was $171.39 \pm 7.95 \mu \mathrm{g} /$ $\mathrm{cm}^{2}$ (table 4), which was statistically different from the $\mathrm{Q}_{\text {ret }}$ values of all the semi-solid preparations $(\mathrm{p}<0.05)$. Among them, the $\mathrm{Q}_{\text {ret }}$ decreased in this order (table 3): hydrophilic cream $\mathrm{F}_{3}>$ lipophilic cream $\mathrm{F}_{2}>$ lipophilic cream $\mathrm{F}_{1}>$ hydrophobic ointment $\mathrm{F}_{0}$. The retained amount ranged from $5.00 \%\left(\mathrm{~F}_{3}\right)$ to $0.80 \%\left(\mathrm{~F}_{0}\right)$. Figure 2 shows that the epidermis was able to release the retained PR-Cl after $\mathrm{F}_{3}$ application: the resulting flux was: $1.25 \pm$ $0.18 \mu \mathrm{g} / \mathrm{cm}^{2} / \mathrm{h}$. Nevertheless, the released amount after $24 \mathrm{~h}$ was $41.10 \pm 11.92 \%$ of the $\mathrm{Q}_{\text {ret }}$, suggesting that the human epidermis acted as a reservoir compartment of $\mathrm{PR}-\mathrm{Cl}$ and released the drug for more than $24 \mathrm{~h}$.

Finally, the hydrophilic cream, which was used also in the permeation studies performed with full-thickness skin, showed only a negligible amount permeated by PR$\mathrm{Cl}$ after $24 \mathrm{~h}\left(<0.01 \mu \mathrm{g} / \mathrm{cm}^{2}\right)$, suggesting that the tested semi-solid vehicles might not be suitable for allowing the drug to reach deep skin levels in non-damaged skin.

\section{The Influence of the Preservative on the Skin \\ Permeation Profile}

As shown in table 4, the highest fluxes of $\mathrm{PR}-\mathrm{Cl}$ were observed in the presence of methylparaben: J of PR-Cl loaded in the hydrophilic cream was 3 times higher in the presence of sodium methylparaben $\left(\mathrm{F}_{3}\right.$ vs. $\left.\mathrm{F}_{4} ; \mathrm{p}<0.01\right)$. These findings were also confirmed by studies carried out 
Table 4. Effect of sodium methylparaben and vehicle $\mathrm{pH}$ on skin permeability parameters of $1 \% \mathrm{w} / \mathrm{w} \mathrm{PR}-\mathrm{Cl}$ delivered by solutions $\left(\mathrm{S}_{1}-\mathrm{S}_{6}\right)$ and semi-solid preparations $\left(\mathrm{F}_{3}, \mathrm{~F}_{4}\right)$

\begin{tabular}{|c|c|c|c|c|c|c|}
\hline & $\begin{array}{l}\text { Sodium } \\
\text { methylparaben }\end{array}$ & Vehicle & $\mathrm{pH}$ & $\mathrm{J}, \mu \mathrm{g} / \mathrm{cm}^{2} / \mathrm{h}$ & $\mathrm{Q}_{\mathrm{P}, 24}, \mu \mathrm{g} / \mathrm{cm}^{2}$ & $\mathrm{Q}_{\text {ret, } 24}, \mu \mathrm{g} / \mathrm{cm}^{2}$ \\
\hline$S_{1}$ & + & Water & 9.1 & $15.40 \pm 3.17$ & $329.85 \pm 67.70$ & $171.39 \pm 7.95$ \\
\hline $\mathrm{S}_{3}$ & + & $\mathrm{PBS}$ at $\mathrm{pH} 9.0$ & 9.0 & $29.00 \pm 2.92$ & $623.57 \pm 67.26$ & $320.65 \pm 103.61$ \\
\hline $\mathrm{S}_{4}$ & - & $\mathrm{PBS}$ at $\mathrm{pH} 9.0$ & 9.0 & $23.94 \pm 7.69$ & $494.79 \pm 119.10$ & $178.49 \pm 17.50$ \\
\hline $\mathrm{S}_{5}$ & + & PBS at pH 5.8 & 5.8 & $0.66 \pm 0.14$ & $12.97 \pm 2.93$ & $341.48 \pm 92.69$ \\
\hline $\mathrm{F}_{3}$ & + & Hydrophilic cream & 6.2 & $2.70 \pm 0.33$ & $52.23 \pm 7.34$ & $94.96 \pm 4.11$ \\
\hline $\mathrm{F}_{4}$ & - & Hydrophilic cream & 6.2 & $0.87 \pm 0.29$ & $19.82 \pm 15.02$ & $79.74 \pm 16.82$ \\
\hline
\end{tabular}

with water solutions of PR-Cl $\left(\mathrm{S}_{1}, \mathrm{~S}_{2}\right)$, where the effect appeared even more significant. However, comparing results of $\mathrm{S}_{1}-\mathrm{S}_{2}$ solutions to those obtained by the $\mathrm{pH}$-buffered ones $\left(\mathrm{S}_{3}-\mathrm{S}_{6}\right)$, it is noteworthy that the enhancement effect attributed to sodium methylparaben was due to the $\mathrm{pH}$ increase of the vehicle. Indeed, the J value of $S_{1}$ was similar to $\mathrm{S}_{3}$ and $\mathrm{S}_{4}$, where $\mathrm{pH}$ was buffered at a value near to the $\mathrm{pK}_{\mathrm{a}}$ of PR $(9.5 \pm 1.2)$ [23]. On the contrary, adjusting the vehicle at the value of 5.8, the impact of preservative was negligible $\left(\mathrm{S}_{5}\right.$ vs. $\left.\mathrm{S}_{6}\right)$ and the J value was comparable to $S_{2}$. The $\mathrm{pH}$ of 5.8 was used because it was similar to the value of the skin surface and of PR, which was almost all ionized. Finally, the paraben also improved the $\mathrm{Q}_{\mathrm{ret}}$, but this effect was less significant in the case of the hydrophilic cream than the water solution. Indeed, the $\mathrm{Q}_{\text {ret }}$ of $\mathrm{S}_{1}$ was slightly higher than the value of $\mathrm{S}_{2}(\mathrm{p}<0.05)$, whereas the results obtained for $\mathrm{F}_{3}$ and $\mathrm{F}_{4}$ were not statistically different $(\mathrm{p}=0.20)$.

\section{Discussion}

The present study focused on the evaluation of the permeation and retention profile of $\mathrm{PR}-\mathrm{Cl}$ delivered by four semi-solid vehicles. Since contradictory data about the effectiveness of topical PR treatment of IH have been reported in the literature, the impact of vehicle composition on in vitro skin permeation through human skin was investigated in depth. Therefore, the tested formulations were chosen among those well known by compounding pharmacists [24] and were similar to those already tested in clinical trials $[1,9,10]$. All the selected preparations were feasible in community or hospital pharmacies and contained cheap excipients that have good compatibility with the drug substance. In particular, the four types of semi-solid preparations considered were a hydrophobic ointment $\left(\mathrm{F}_{0}\right)$, two lipophilic creams $\left(\mathrm{F}_{1}, \mathrm{~F}_{2}\right)$, and a hydrophilic cream $\left(\mathrm{F}_{3}\right)$. The two lipophilic creams differed in the content of emulsifiers or dispersing agents and have a very limited amount of water. The four preparations also differed in relation to the method of incorporating the $\mathrm{PR}-\mathrm{Cl}$ : directly as solid salt $\left(\mathrm{F}_{0}\right)$ or as water solution $\left(\mathrm{F}_{1}-\mathrm{F}_{3}\right)$. All of them showed an acceptable uniformity of drug content and were stable at room temperature for at least 6 months after the preparation (data not shown).

The PR-Cl concentration at the therapeutic site after topical application has been directly related to its ability to penetrate the stratum corneum and to permeate through the human epidermis. However, the drug should firstly diffuse through the semi-solid matrix and be released to allow skin penetration.

In general, the drug released from a semi-solid matrix can be described by models derived by the Higuchi equation $[18,25]$. In particular, if the drug was dissolved in the matrix, the cumulative released amount $(\mathrm{m})$ can be calculated by the following Eq. 3:

$$
m=2 \times C_{0} \sqrt{\frac{D_{m} t}{\pi}},
$$

where $\mathrm{D}_{\mathrm{m}}$ is the drug diffusion coefficient, $\mathrm{C}_{0}$ is the drug solubility in the releasing matrix, and $t$ is the time.

On the other hand, when the drug is dispersed as solid in the semi-solid matrix, Eq. 3 cannot be applied and $\mathrm{m}$ can be described by Eq. 4:

$$
m=\sqrt{2 \times D_{m} \times C_{s} \times\left(Q-\frac{C_{s}}{2}\right) \times t},
$$

where $\mathrm{C}_{\mathrm{s}}$ is the saturated drug solubility and Q is the total drug amount in the semi-solid matrix. If $\mathrm{Q}$ resulted $>>$ 
$\mathrm{C}_{s}$, as expected in the case of formulation $\mathrm{F}_{0}$, then Eq. 4 is transformed in Eq. 5.

$$
m=\sqrt{2 \times D_{m} \times C_{s} \times Q \times t} .
$$

According to Eq. 3, the drug release from the hydrophobic ointment $\mathrm{F}_{0}$ was not only governed by the drug loading $(\mathrm{Q})$, but also by $\mathrm{C}_{\mathrm{s}}$ and $\mathrm{D}_{\mathrm{m}}$. In particular, considering that the drug loading of $\mathrm{F}_{0}$ was equal to the other semisolid formulations, the negligible release rate reported in table 3 for $F_{0}$ suggested that $C_{s}$ and $D_{m}$ were the bottleneck parameters of the drug release process due to the low drug solubility and diffusion through the white petrolatum. On the contrary, the dissimilarities observed in the release rates for the other semi-solid formulations might be related only to changes in $\mathrm{D}_{\mathrm{m}}$ (Eq. 3). Indeed, since $\mathrm{PR}-\mathrm{Cl}$ was dissolved before incorporation into the semi-solid matrix, $\mathrm{C}_{0}$ could be considered similar among formulations $\mathrm{F}_{1}-\mathrm{F}_{3}$, and therefore the release profiles could be influenced only by the changes in drug diffusion through the semi-solid matrix due to the dissimilar composition of the vehicles. To support such a hypothesis, solubility parameters $(\delta)$ were calculated for the lipophilic part of $\mathrm{F}_{0}-\mathrm{F}_{2}$ (table 2 ), as proposed by Vaughan [20]. The derived $\delta$ values increased in function as the percentage of amphiphilic excipients in the semi-solid formulation: $\mathrm{F}_{0}\left(7.33 \mathrm{cal} / \mathrm{cm}^{3}\right)>\mathrm{F}_{1}\left(7.47 \mathrm{cal} / \mathrm{cm}^{3}\right)>\mathrm{F}_{2}$ $\left(8.44 \mathrm{cal} / \mathrm{cm}^{3}\right)$. Considering that the $\delta$ value of $\mathrm{PR}$ as $12.02 \mathrm{cal} / \mathrm{cm}^{3}$, the higher the $\delta$ value of the semi-solid matrix, the higher the drug solubility and, therefore, $\mathrm{D}_{\mathrm{m}}$. Indeed, the release profiles of $\mathrm{F}_{0}-\mathrm{F}_{2}$ were strongly influenced by the solubility parameters $\left(R^{2}=0.99\right)$. In particular, the release rate of $\mathrm{F}_{0}$ was the lowest since PR-Cl cannot be solubilized significantly in white petrolatum (lowest $\delta$ value), whereas the highest affinity of PR for the matrix of $\mathrm{F}_{2}$ resulted in the highest drug release.

In the case of creams, the solubility parameters cannot be applied since creams were more complex systems and had a higher amount of water. In particular, the results suggested that the water percentage could also influence the drug release from the cream formulations $\left(\mathrm{F}_{1}-\mathrm{F}_{4}\right)$. Indeed, comparing the release rate of the three creams, it is worth observing that the higher the water percentage, the higher the release through the semi-solid matrix. Indeed, the release rate from hydrophilic cream $\left(\mathrm{F}_{3}\right)$ was 25 times higher than hydrophobic cream $\left(\mathrm{F}_{2}\right)$, which contained 4 times less water (tables 2, 3).

These results were also substantiated by the human epidermis permeation/retention profiles. The hydrophobic ointment was confirmed to be the worst semi-solid matrix in terms of permeated amount, whereas the hy- drophilic cream guaranteed the best performance. In the case of lipophilic creams, the results showed that the $\mathrm{F}_{2}$ formulation guaranteed a higher permeation amount after $24 \mathrm{~h}$ than $\mathrm{F}_{1}$. However, both formulations were not able to reach a linear permeation profile within $24 \mathrm{~h}$.

The permeation of a molecule through the human epidermis may be modelled as a passive diffusion process described by the modified first Fick law (Eq. 6):

$$
J=K_{S C / W} \times D_{S C E} \times A \times \frac{C_{d}-C_{r}}{h},
$$

where $J$ is the permeation rate through the human epidermis, $\mathrm{K}_{\mathrm{SC} / \mathrm{W}}$ is the partition coefficient between donor phase and stratum corneum, $\mathrm{D}_{\mathrm{SCE}}$ is the diffusion coefficient, $\mathrm{A}$ is the application area, $\mathrm{C}_{\mathrm{d}}$ and $\mathrm{C}_{\mathrm{r}}$ are the drug concentrations at the two layers of the human epidermis, and $h$ is the thickness of the membrane.

By a comparison of the release and permeation results, direct correlations between the release rate and $\mathrm{Q}_{\mathrm{P}, 24}$ $\left(R^{2}=0.93\right)$ and $Q_{\text {ret }}$ were observed $\left(R^{2}=0.79\right)$, suggesting that permeation and retention processes were mainly influenced by vehicle effectiveness in drug releasing at the skin surface. In particular, as shown by Eq. 4 , the higher the release rate, the higher $\mathrm{C}_{\mathrm{d}}$ and, therefore, J. However, the formulation performances in drug release cannot completely describe the results obtained in permeation and retention studies. Indeed, although the release rate of the $\mathrm{F}_{3}$ cream was about 20 times higher than the $\mathrm{F}_{2}$ cream, the ratios between the $\mathrm{Q}_{\mathrm{P}, 24}$ and $\mathrm{Q}_{\text {ret }}$ values of the two formulations were equal to 3.5 and 1.7 , respectively. On the other hand, unlike permeation data, the retention results suggested that hydrophobic ointment was able to release enough PR-Cl to reach a detectable retained drug amount in the human epidermis after $24 \mathrm{~h}$. Considering the drug affinity of white petrolatum previously discussed, the observed $\mathrm{Q}_{\text {ret }}$ of $\mathrm{F}_{0}$ might be related to the dissolution of drug crystals, which were homogenously dispersed in the hydrophobic ointment at the interface between the skin and the semi-solid formulation. On the contrary, the retention process of $\mathrm{PR}-\mathrm{Cl}$ delivered by other formulations was strictly related to the permeation process sustained by the concentration gradient between the membrane surface and the receptor compartment. As a matter of fact, the semi-solid vehicle itself is able to influence in many ways the permeation of molecules through the human epidermis $[15,16]$. In addition to a direct effect on the drug concentration gradient, characteristics of semisolid bases impact indirectly on $\mathrm{K}_{\mathrm{SC} / \mathrm{W}}$ and $\mathrm{D}_{\mathrm{SCE}}$, inducing modifications in the inner structure of the stratum corneum $[13,26]$. For example, the higher in vivo perfor- 
mance of lipophilic creams in comparison to the observed in vitro pattern could be due to the enhancement of drug permeation related to the occlusive properties of the semi-solid matrix $[17,26]$. Indeed, lipophilic creams, which are more occlusive than hydrophilic ones, can alter the skin permeability of molecules by increasing the water content in the human epidermis. Higher occlusive properties may explain why clinical studies showed comparable clinical efficacy for PR-Cl-loaded hydrophilic, lipophilic creams or ointments $[1,9]$.

The results obtained by the epidermis drug release study highlighted that the human epidermis was able to be a reservoir compartment of $\mathrm{PR}-\mathrm{Cl}$ [27], allowing prolongation of the drug diffusion to the lower layers of human skin after the removal of the topical preparation. Figure 2 shows that the human epidermis was able to release about $40 \%$ of the retained drug amount within the first $24 \mathrm{~h}$ after removal. Indeed, the amount of drug retained in the human epidermis could diffuse to the superficial IH maintaining a clinical effect. Therefore, beyond the permeation profiles, the vehicle effectiveness in sustaining the drug partition in the human epidermis was interesting since the penetrated drug amount could then diffuse slowly into a deeper layer. In particular, lipophilic creams should also take advantage of the occlusive effect and be able to sustain drug penetration in the human epidermis. Furthermore, the possibility of having a low PR-Cl-permeated amount seems interesting for the design of a topical preparation intended to treat newborn infants. The limited drug release and permeation profiles of lipophilic creams can be advantageous in such patients because of their skin barrier being more permeable to xenobiotics in comparison to adults or children older than 3 years $[28,29]$.

Finally, the negligible permeation through the fullthickness skin may suggest that the topical PR preparations were not able to increase the concentration gradient enough between the membrane layers to allow the permeation of PR-Cl through the dermal layer. Therefore, the use of permeation enhancers should be considered for improving the PR-Cl flux if the goal is to reach therapeutic sites located in deeper layers of the human skin.

If such results can explain the clinical evidence reported in the literature on the low efficacy of topical PR in IH with deeper elements $[1,7]$, the findings also suggest that the use of topical preparation might be related to low PR$\mathrm{Cl}$ systemic concentration, with a low incidence of systemic side effects due to the low permeation profile.

The addition of a preservative to a semi-solid preparation containing water was required for inhibiting the microbiological growth. Aiming to investigate the techno-

Propranolol-Loaded Semi-Solid

Preparations for Treating Haemangiomas logical criticisms related to the topical delivery of PR by semi-solid formulations, sodium methylparaben was used as a model preservative because of its physicochemical properties and its wide use in cosmetics and pharmaceutical products. Concerning parabens, it is also noteworthy that antimicrobial activity is $\mathrm{pH}$ dependent: for methylparaben, the optimum activity was when the $\mathrm{pH}$ ranged between 4 and 8 [30]. Moreover, even if the use of parabens in pharmaceutical preparations is common, they have recently been associated with hormonal dysfunctions due to their penetration through the human epidermis [31, 32]. In particular, Darbre et al. [33] published a study in 2004 revealing that methylparaben was found in human breast tumours and opening the scientific debate about the role of parabens in such tumours. Therefore, as final extemporaneous creams may or not have parabens, a batch of hydrophilic cream was prepared without preservative $\left(\mathrm{F}_{4}\right)$ for investigating how such an excipient altered the $\mathrm{PR}-\mathrm{Cl}$ permeation profiles. Interestingly, the results showed a decrease of permeation and retention profiles for the formulations without the preservative. Further studies on aqueous solutions of $\mathrm{PR}-\mathrm{Cl}$ with or without the preservative at different $\mathrm{pH}$ (5.8 and 9.0) suggested that the improvement related to the presence of the preservative was due to the $\mathrm{pH}$ increase in the hydrophilic environment of the formulation (table 4). From the comparison of the $\mathrm{pH}$ results obtained by solutions and creams, it is possible to observe that in the former the gap was bigger than in the latter. This incongruity may be justified considering that creams are more complex systems than solutions and that their inner $\mathrm{pH}$ is also influenced by the excipients added to the formulation, which can minimize the $\mathrm{pH}$ changes induced by the addition of acid or bases, like sodium methylparaben. As shown in table 4, sodium methylparaben in solution induced a shift of $\mathrm{pH}$ to a value near the $\mathrm{pK}_{\mathrm{a}}$ of PR $(9.5 \pm$ 1.2) [21]. In line with the Henderson-Hasselbalch equation, the inner $\mathrm{pH}$ of the aqueous phase of the semi-solid formulation modifies the ionization equilibrium of $\mathrm{PR}-\mathrm{Cl}$ and the PR-free base, which penetrates easily through the human epidermis [13]. In particular, when the $\mathrm{pH}$ is near the $\mathrm{pK}_{\mathrm{a}}$ of $\mathrm{PR}$, the concentration of free base increases, inducing an increase in the permeation flux due to more appropriate physicochemical characteristics for the absorption process. In agreement with Chantasart et al. [14], this evidence highlights that an increase in the $\mathrm{pH}$ of the delivery system was related to higher permeability coefficients of PR through the human epidermis.

Therefore, the addition of excipients, which influence $\mathrm{pH}$ formulation, should be critically considered and test- 
ed to avoid a high variability in the topical bioavailability of a drug. Furthermore, if $\mathrm{pH}$-sensitive excipients were included in the semi-solid formulation, their impact on the excipient-related properties (e.g., antimicrobial effectiveness) should also be investigated. If their use cannot be avoided, the selection of an appropriate buffer system should be taken in account. Although the hydrophilic cream was tested as a preparation model for studying the effect of methylparaben due to the high amount of water, the outcomes were also applicable to all the formulations considered in this paper where the preservative was added to the formulation. In particular, the $\mathrm{pH}$ increase might be particularly critical also in the case of lipophilic creams since the PR base might diffuse easier than PR-Cl through the hydrophobic semi-solid base.

\section{Conclusion}

The use of PR in the treatment of IH has become popular in the last decades due to the amazing effectiveness and the low incidence of side effects. Starting with the success of oral treatment, the topical delivery of PR began to be considered for the treatment of superficial $\mathrm{IH}$, especially for patients more sensitive to the side effects of oral treatment (e.g., newborn infants). The present study rationalized the selection of a semi-solid vehicle by in vitro screening, highlighting the most critical formulative aspects for dermal delivery of $\mathrm{PR}-\mathrm{Cl}$ and identifying different vehicle candidates according to the patient's age. The results confirmed that $\mathrm{PR}-\mathrm{Cl}$ was able to permeate and to concentrate in the upper layer of the human skin, although its behaviour was strongly affected by formulative choice. In particular, the impact of different technological features of semi-solid vehicles, such as the importance of good drug solubilization in the semi-solid matrix and the influence of $\mathrm{pH}$ value on the microenvironment of the matrix, was pointed out in the $\mathrm{PR}-\mathrm{Cl}$ penetration. Moreover, the in vitro results on full-thickness skin suggested a negligible permeation pattern that could suggest lower systemic side effects induced by topical PR rather than oral treatment and confirm the low effectiveness of topical PR in treating IH with deep elements. Besides the direct implications of this evidence, it may be considered a useful example to emphasize that compounding pharmacists should carefully choose the excipients of extemporaneous preparations, considering both their well-known function-related properties and their possible physicochemical interactions with the other formula components, to rationalize the technological properties of the final formulation.

The overall results discussed in this paper may be useful, therefore, for compounding pharmacists and physicians for driving the selection of the semi-solid matrix according to the therapeutic needs and on the basis of patient features. In particular, the results obtained by the in vitro permeation studies might be helpful to compounding pharmacists for choosing the best semi-solid drug product for the treatment of $\mathrm{IH}$ in patients with a higher risk of incurring cardiac side effects (e.g., newborn infants).

\section{Statement of Ethics}

Informed consent for the use of biological samples for research purposes was signed.

\section{Disclosure Statement}

No financial support was received for this submission. None of the authors has any conflict of interest with this submission.

\section{References}

1 Bonifazi E, Mazzotta F, Colonna V, De Leo E, Milano A: Topical propranolol in the superficial infantile hemangioma of the skin. Eur J Pediatr Dermatol 2010;20:247-251.

$\checkmark 2$ Zimmermann AP, Wiegand S, Werner JA, Eivazi B: Propranolol therapy for infantile haemangiomas: review of the literature. Int J Pediatr Otorhinolaryngol 2010;74:338-342.

$>3$ Léauté-Labrèze C, de la Roque ED, Hubiche T, Boralevi F, Thambo J-B, Taïeb A: Propranolol for severe hemangiomas of infancy. $\mathrm{N}$ Engl J Med 2008;358:2649-2651.
4 Gomulka J, Siegel DH, Drolet BA: Dramatic shift in the infantile hemangioma treatment paradigm at a single institution. Pediatr Dermatol 2013;30:751-752.

5 Storch CH, Hoeger PH: Propranolol for infantile haemangiomas: insights into the molecular mechanisms of action. Br J Dermatol 2010;163:269-274.

-6 Hogeling M, Adams S, Wargon O: A randomized controlled trial of propranolol for infantile hemangiomas. Pediatrics 2011;128:e259e266.
7 Bonifazi E, Colonna V, Mazzotta F, Balducci G, Laforgia N: Propranolol in rapidly growing hemangiomas. Eur J Pediatr Dermatol 2008; 18:185-192.

8 Zaher H, Rasheed H, Esmat S, Hegazy RA, Gawdat HI, El-Komy M, Abdelhalim DM: Propranolol and infantile hemangiomas: different routes of administration, a randomized clinical trial. Eur J Dermatol 2013;23:646652 .

9 Kunzi-Rapp K: Topical propranolol therapy for infantile hemangiomas. Pediatr Dermatol 2012;29:154-159. 
10 Xu G, Lv R, Zhao Z, Huo R: Topical propranolol for treatment of superficial infantile hemangiomas. J Am Acad Dermatol 2012;67: 1210-1213.

11 Wang L, Xia Y, Zhai Y, Li C, Li Y: Topical propranolol hydrochloride gel for superficial infantile hemangiomas. J Huazhong Univ Sci Technolog Med Sci 2012;32:923-926

12 Kumar MG, Coughlin C, Bayliss SJ: Outpatient use of oral propranolol and topical timolol for infantile hemangiomas: survey results and comparison with propranolol consensus statement guidelines. Pediatr Dermatol 2015; 32:171-179.

13 Cilurzo F, Minghetti P, Alberti E, Gennari CGM, Pallavicini M, Valoti E, Montanari L: An investigation into the influence of counterion on the RS-propranolol and S-propranolol skin permeability. J Pharm Sci 2010;99: 1217-1224.

14 Chantasart D, Hao J, Li SK: Evaluation of skin permeation of $\beta$-blockers for topical drug delivery. Pharm Res 2013;30:866-877.

15 Wagner H, Kostka K-H, Adelhardt W, Schaefer UF: Effects of various vehicles on the penetration of flufenamic acid into human skin. Eur J Pharm Biopharm 2004;58:121-129.

16 Minghetti P, Casiraghi A, Cilurzo F, Tosi L, Montanari L, Trespidi L: Formulation study and anti-inflammatory efficacy of topical semi-solids containing a nitro ester of flurbiprofen. Skin Pharmacol Appl Skin Physiol 2003;16:91-99.

17 Casiraghi A, Ardovino P, Minghetti P, Botta C, Gattini A, Montanari L: Semisolid formu- lations containing dimethyl sulfoxide and a-tocopherol for the treatment of extravasation of antiblastic agents. Arch Dermatol Res 2007;299:201-207.

18 Higuchi T: Physical chemical analysis of percutaneous absorption process from creams and ointments. J Cosmet Sci 1960;11:85-97.

19 Cilurzo F, Vistoli G, Selmin F, Gennari CGM, Musazzi UM, Franzé S, Lo Monte M, Minghetti P: An insight into the skin penetration enhancement mechanism of N-methylpyrrolidone. Mol Pharm 2014;11:1014-1021.

20 Vaughan CD: Using solubility parameters in cosmetics formulation. J Soc Cosmet Chem Jpn 1985;36:319-333.

21 Maitani Y, Coutel-Egros A, Obata Y, Nagai T: Prediction of skin permeabilities of diclofenac and propranolol from theoretical partition coefficients determined from cohesion parameters. J Pharm Sci 1993;82:416-420.

22 Squillante E, Needham T, Zia H: Solubility and in vitro transdermal permeation of nifedipine. Int J Pharm 1997;159:171-180.

23 Modamio P, Lastra CF, Mariño EL: A comparative in vitro study of percutaneous penetration of $\beta$-blockers in human skin. Int J Pharm 2000;194:249-259.

24 Farmacopea ufficiale della repubblica italiana, ed XII. Rome, Istituto Poligrafico e Zecca dello Stato, 2008.

25 Olejnik A, Goscianska J, Nowak I: Active compounds release from semisolid dosage forms. J Pharm Sci 2012;101:4032-4045.

26 Cevc G, Mazgareanu S, Rother M, Vierl U: Occlusion effect on transcutaneous NSAID delivery from conventional and carrier-based formulations. Int J Pharm 2008;359:190-197.

27 Yagi S, Nakayama K, Kurosaki Y, Higaki K, Kimura T: Factors determining drug residence in skin during transdermal absorption: studies on $\beta$-blocking agents. Biol Pharm Bull 1998;21:1195-1201.

28 Kanti V, Bonzel A, Stroux A, Proquitté H, Bührer C, Blume-Peytavi U, Garcia Bartels N: Postnatal maturation of skin barrier function in premature infants. Skin Pharmacol Physiol 2014;27:234-241.

29 Walters RM, Khanna P, Chu M, Mack MC: Developmental changes in skin barrier and structure during the first 5 years of life. Skin Pharmacol Physiol 2016;29:111-118.

30 Johnson R, Steer R: Methylparaben monograph; in Rowe RC, Sheskey PJ, Weller PJ (eds): Handbook of Pharmaceutical Excipients, ed 5. Washington, Pharmaceutical Press, 2006, pp 466-470.

31 Prusakiewicz JJ, Harville HM, Zhang Y, Ackermann C, Voorman RL: Parabens inhibit human skin estrogen sulfotransferase activity: possible link to paraben estrogenic effects. Toxicology 2007;232:248-256.

- 32 Caon T, Costa ACO, de Oliveira MAL, Micke GA, Simões CMO: Evaluation of the transdermal permeation of different paraben combinations through a pig ear skin model. Int J Pharm 2010;391:1-6.

-33 Darbre PD, Aljarrah A, Miller WR, Coldham NG, Sauer MJ, Pope GS: Concentrations of parabens in human breast tumours. J Appl Toxicol 2004;24:5-13.
Propranolol-Loaded Semi-Solid

Preparations for Treating Haemangiomas
Skin Pharmacol Physiol 2016;29:210-219 